\title{
Post Operative Pulmonary Complications Following Surgery for Congenital Heart Disease
}

\author{
MNA HASAN ${ }^{\mathrm{a}}$, M SHARIFUZZAMAN $^{\mathrm{b}}$, AK SHAMSUDDIN $^{\mathrm{c}}$, SK BISWAS $^{\mathrm{d}}, \mathrm{J} \mathrm{HOSSAIN}^{\mathrm{e}}$, MRA SHEIKH $^{\mathrm{f}}$
}

\begin{abstract}
:
Objective: To identify the incidence and related factors for pulmonary complications and its impact on outcome in patients subjected to surgery for congenital heart disease (CHD).

Methods: The sample comprised 141 patients of both genders, subjected to surgery for $\mathrm{CHD}$, during 3 months period from $1^{\text {st }}$ July 2014 to $30^{\text {th }}$ September 2014. The data were obtained from newly improvised Congenital Heart Surgery Database.

Results: Twenty eight (20\%) patients developed some form of pulmonary complications. Age, weight, length and body surface area are significantly low among them $(p<0.05)$. They also have higher Aristotle score \& RACHS score, higher $C P B$ time and aortic cross clamp time $(p<0.01)$. Patients
\end{abstract}

Introduction:

Although minimal invasive catheter based treatment for congenital heart diseases (CHD) are possible now a days ${ }^{1}$, surgery remains as an important modality for treating most congenital cardiac malformations ${ }^{2}$. Pulmonary complications with wide variation of

a. Dr. M Nurul Akhtar Hasan, Pediatric Intensivist \& Assistant Professor, Pediatric Cardiac ICU, NHFH\&RI, Mirpur, Dhaka.

b. Prof. M Sharifuzzaman, Senior Consultant \& Professor of Cardiac Surgery, NHFH\&RI, Mirpur, Dhaka.

c. Dr. Abul Kalam Shamsuddin, Senior Consultant \& Associate Professor of Pediatric Cardiac Surgery, NHFH\&RI, Mirpur, Dhaka.

d. Dr. Samir Kumar Biswas, Senior Consultant \& Associate Professor of Cardiac Surgery, NHFH\&RI, Mirpur, Dhaka

e. Dr. Dr. Jesmin Hossain, Pediatric Cardiologist \& Assistant Professor, Pediatric Cardiology, NHFH\&RI, Mirpur, Dhaka.

f. Dr. Mohammad Rahamat Ali Sheikh, Senior Medical Officer, Pediatric Cardiac ICU, NHFH\&RI, Mirpur, Dhaka

Address of Correspondence: Dr. M Nurul Akhtar Hasan, Pediatric Intensivist \& Assistant Professor, Pediatric Cardiac ICU, National Heart Foundation Hospital \& Research Institute, Mirpur-2, Dhaka, Bangladesh. Mobile: (+88)01911249062, Email: bipul_304957@yahoo.com

Received: 2 March 2015

Accepted: 3 February 2017 who had pulmonary complications had significantly higher ( $p<0.01)$ vasoactive inotrope score, prolonged mechanical ventilation, longer post operative ICU stay and post operative hospital stay. There was no mortality.

Conclusions: Pulmonary complications are common after surgery for CHD which is more common in small children and complex surgeries. It significantly affects outcome including duration of mechanical ventilation and length of stay but no effect in mortality.

Keywords: Congenital heart disease, post operative, pulmonary complications.

(J Bangladesh Coll Phys Surg 2017; 35: 52-60)

incidence, ranging from $6 \%$ to $76 \%$ are the most common causes of morbidity and mortality in surgeries for $\mathrm{CHDs}^{3}$. Children and adolescent with CHD who underwent surgical repair are a special group of patients associated with an increased risk of development of post-operative pulmonary complications ${ }^{4}$. Popular believe is that general anesthesia, surgical incision, cardiopulmonary bypass (CPB), ischemia time, intensity of surgical manipulation and number of drains may predispose patients to pulmonary function changes, which are highly relevant on the onset of pulmonary complications in cardiac surgery postoperative ${ }^{3}$. Most complications such as pneumonitis, bronchospasm, lobar collapse, prolonged mechanical ventilation and generalized pulmonary dysfunction develop as a result of changes in lung volumes that occur in response to dysfunction of muscles of respiration and other changes in chest wall mechanics ${ }^{4}$. All of these have effect on outcomes in term of duration of mechanical ventilation, length of ICU stay and post operative morbidity. Department of Cardiac Surgery of National Heart Foundational Hospital \& Research Institute is performing surgery for CHDs on regular basis. But we did not have any previous organized documentation of respiratory event in these patients. There is no other 
literature also in this issue published in Bangladesh. Recently Department of Pediatric Cardiac Intensive Care has improvised Congenital Heart Surgery Database. Therefore, this initial report aims at identifying the post operative pulmonary events and their effect on outcome.

\section{Methodology:}

This is a retrospective cohort study, executed at National Heart Foundation Hospital \& Research Institute (NHFH\&RI) in the city of Dhaka, Bangladesh. The study sample consisted of all children as well as few grown up and adult patients of both genders, diagnosed with CHDs, subjected to cardiac surgery, during 3 months period from $1^{\text {st }}$ July 2014 to $30^{\text {th }}$ September 2014.

\section{Data collection:}

Data collection was executed from newly improvised "The Congenital Heart Surgery Database" in the Department of Pediatric Cardiac Intensive Care. The data collection instrument approached issues related to: Demographic characters, diagnosis, procedures performed, pulmonary complication, types of pulmonary complications, pulmonary pressure, cardiopulmonary bypass, postoperative mechanical ventilation, ICU stay and post operative hospital stay, procedure risk scores, post operative inotrope score and vasoactive inotrope score

\section{Operational method of the database:}

"The Congenital Heart Surgery Database" of the Department of Pediatric Cardiac Intensive Care has been started since $1^{\text {st }}$ July 2014. Every day one data entry operator entered the cases of the day and also the detail data entry of the patients who were shifted out of intensive care unit (ICU). On the same day resident medical officer recheck all the data entry of that day. On the day of discharge pediatric intensivist again check all the data entry of that patient and complete the entry of that particular patient. To make the database having minimal error, periodic analysis of the database is also done.

\section{Case selection:}

During the period of time from $1^{\text {st }}$ July -30 September 2014 ( 3 months) we had total 144 cases. Among them there were 2 deaths, which were excluded from the analysis. Among the remaining 142 cases one patient is still in ICU under mechanical ventilation during writing the manuscript. He was also excluded from the analysis. So final analysis was done over remaining 141 cases.

\section{Statistical analysis:}

All data were computed using the Microsoft Excel 2010 software and analyzed with SPSS $®$ statistical software version 16 (SPSS Inc., Chicago, IL). Continuous data are expressed as Median and Interquartile range (IQR) and categorical data are expressed as Percentage. Depending on the distribution a Student's t test or Mann-Whitney U test was performed. Categorical variables were compared using the chi squared test and if expected frequencies less than five were found in contingency tables Fisher's exact test was used. All statistical tests were two-tailed. $P$ values of less than 0.05 were considered statistically significant

\section{Results:}

The demographic characteristics of the studied patients (141 cases) showed [Table -1] that median age of the cohort was 60 months with interquartile range (IQR) 27 -132 months. Median weight of $14.6 \mathrm{~kg}$ with IQR $9.8-$ $28.5 \mathrm{~kg}$ and median length $100 \mathrm{~cm}$ with IQR $82-141 \mathrm{~cm}$. Sixty four $(45 \%)$ were male and $77(55 \%)$ were female. Two (1.4\%) patients had Down syndrome. Pulmonary arterial hypertension (PAH) was present among 105 (74.5\%) patients with median PASP $41 \mathrm{mmHg}$, IQR 35 $52 \mathrm{mmHg}$.

Concerning the clinical diagnosis [Table - 2], $111(78.7 \%)$ were acyanotic CHDs, mostly shunt lesions. Twenty six

Detail of the patients excluded are as follows:

\begin{tabular}{|c|c|c|c|c|}
\hline$\overline{\text { Age }}$ & Sex & Diagnosis & Operation & Outcome \\
\hline $2 \mathrm{~m} 5 \mathrm{~d}$ & M & TGA, IVS & ASO & $\begin{array}{l}\text { Expired on } 1^{\text {st }} \text { POD due to bleeding } \\
\text { and low output syndrome }\end{array}$ \\
\hline $8 \mathrm{~d}$ & M & $\begin{array}{l}\text { Complete common AVSD, PA, } \\
\text { PDA dependent circulation }\end{array}$ & MBTS & $\begin{array}{l}\text { Expired on } 5^{\text {th }} \text { POD due to down } \\
\text { syndrome, sepsis, respiratory failure }\end{array}$ \\
\hline $14 \mathrm{~m}$ & M & TGA, IVS & $\begin{array}{l}\text { Senning procedure, } \\
\text { TV repair }\end{array}$ & $\begin{array}{l}\text { Still in ICU with mechanical ventilation with } \\
\text { tracheotomy on } 92^{\text {nd }} \text { POD. }\end{array}$ \\
\hline
\end{tabular}

TGA: Transposition of great arteries, IVS: Intact ventricular septum, ASO: Arterial switch operation, AVSD: Atrioventricular septal defect, PA: Pulmonary atresia, PDA: Patent ductus arteriosus, MBTS: Modified Blalock Taussig shunt, POD: Post operative days, TV: Tricuspid valve, ICU: Intensive care unit 


\section{Table-I}

\section{Demographics $(N=141)$}

\begin{tabular}{lcc} 
Variable & Median $(\mathrm{IQR})$ & $\mathrm{n}(\%)$ \\
\hline Age (months) & $60(27-132)$ & \\
Weight $(\mathrm{kg})$ & $14.6(9.8-28.5)$ & \\
Length $(\mathrm{cm})$ & $100(82-141)$ & \\
Sex distribution & & \\
$\quad$ Male & $64(45)$ & $2(1.4)$ \\
$\quad$ Female & $77(55)$ & $105(74.5)$ \\
Down syndrome & & \\
Pulmonary artery hypertension & $41(35-52)$ & \\
PASP (mmHg), n=105 & & \\
IQR: Interquartile range, PASP: pulmonary artery systolic pressure & \\
\hline
\end{tabular}

Table-II

\section{Diagnosis $(N=141)$}

\section{Diagnosis}

Acyanotic heart disease

Patent ductus arteriosus (PDA)

Atrial septal defect (ASD)

ASD, Partial anomalous pulmonary venous circulation (PAPVC)

ASD, Mital valve (MV) disease

Ventricular septal defect (VSD)

ASD, VSD

ASD, PDA

VSD, PDA

ASD, Pulmonary stenosis (PS)

VSD, PS

Atrio-ventricular septal defect (AVSD), (partial)

AVSD (complete)

Others

Cyanotic heart disease with increased PBF

Double outlet right ventricle (DORV), Transposition of great artery (TGA) variety

TGA, Intact ventricular septum (IVS)

TGA, VSD

Total anomalous pulmonary venous circulation (TAPVC)

Cyanotic heart disease with decrease PBF

VSD, Pulmonary atersia (PA)

Tetralogy of Fallot (TOF)

TOF, ASD

TOF, PDA

TOF, ASD, PDA

DORV, TOF variety

DORV, TGA variety, PS

PA, VSD

Tricuspid atresia
$\mathrm{N}(\%)$

111(78.7)

$19(13.5)$

$30(21.3)$

$5(3.5)$

$9(6.4)$

$32(22.7)$

$1(0.7)$

2(1.4)

4(2.8)

$1(0.7)$

4(2.8)

2(1.4)

$1(0.7)$

$1(0.7)$

$4(2.8)$

$1(0.7)$

$1(0.7)$

$1(0.7)$

$1(0.7)$

26(18.4)

$4(2.8)$

$9(6.4)$

$3(2.1)$

$3(2.1)$

2(1.4)

$2(1.4)$

$1(0.7)$

$1(0.7)$

$1(0.7)$

PBF: pulmonary blood flow 
(18.4\%) patients had cyanotic CHDs with decreased pulmonary blood flow and remaining $4(2.8 \%)$ had cyanotic CHDs with increased pulmonary blood flow. Among acyanotic heart disease patients most common being VSD 32 (22.7\%) and ASD 30 (21.3\%) followed by PDA 19 (13.5\%), ASD with mitral valve disease 9 (6.4\%) and other combinations. Cyanotic heart diseases with decreased pulmonary flow patients are mostly TOF and TOF variants. Among the procedures performed [Table
- 3] most common being ASD closure 34 (24.3\%) followed by VSD closure 30 (21.4\%), PDA ligation 20 (14.3\%), Total correction of TOF 17 (12.1\%) and few other procedures.

Cardiopulmonary bypass (CPB) was required in 117 (83\%) surgeries with median CPB time of 82 min with IQR $66-116$ min and median cross clamp time was 52 min with IQR $35.5-76 \mathrm{~min}$ [Table-IV].

\section{Table-III}

\begin{tabular}{lc} 
& \\
& Procedures $(N=141)$ \\
Procedures & $\mathrm{N}(\%)$ \\
\hline RACHS -1 & $60(42.9)$ \\
PDA ligation & $20(14.3)$ \\
ASD closure & $34(24.3)$ \\
ASD closure, PAPVC rerouting & $5(3.6)$ \\
ASD closure, PDA ligation & $1(0.7)$ \\
RACHS -2 & $61(43.6)$ \\
VSD closure & $30(21.4)$ \\
ASD closure, VSD closure & $1(0.7)$ \\
VSD closure, PDA ligation & $4(2.9)$ \\
ASD closure, RVOT procedure & $1(0.7)$ \\
VSD closure, RVOT procedure & $7(5)$ \\
Total correction of TOF & $17(12.1)$ \\
TAPVC rerouting & $1(0.7)$ \\
RACHS -3 & $18(12.9)$ \\
ASD closure, MV repair & $5(3.6)$ \\
VSD closure, MV or Tricuspid valve (TV) procedure & $2(1.4)$ \\
VSD closure, RVOT procedure, AV repair & $1(0.7)$ \\
Partial AVSD repair & $2(1.4)$ \\
Complete AVSD repair & $1(0.7)$ \\
Senning operation & $2(1.4)$ \\
Rastelli procedure & $1(0.7)$ \\
Modified Blalock Taussig Shunt (MBTS) & $2(1.4)$ \\
BiDirectional Glenn shunt (BDG shunt) & $1(0.7)$ \\
Others & $1(0.7)$ \\
RACHS-4 & $1(0.7)$ \\
Arterial switch operation (ASO) & $1(0.7)$ \\
\hline RACHS: Risk Adjustment in Congenital Heart Surgery, RVOT: right ventricular outflow tract, \\
\hline
\end{tabular}




\section{Table-IV}

Perfusion data $(n=141)$

\begin{tabular}{lcc} 
Variable & Median $(\mathrm{IQR})$ & $\mathrm{n}(\%)$ \\
\hline CPB status & & \\
$\quad$ CPB & $117(83)$ \\
$\quad$ Off CPB & $24(17)$ \\
CPB time (min)** & $82(66-116)$ \\
Cross clamp time $(\min )^{* *}$ & $52(35.5-76)$ \\
\hline
\end{tabular}

** $\mathrm{n}=117$

Pulmonary complication

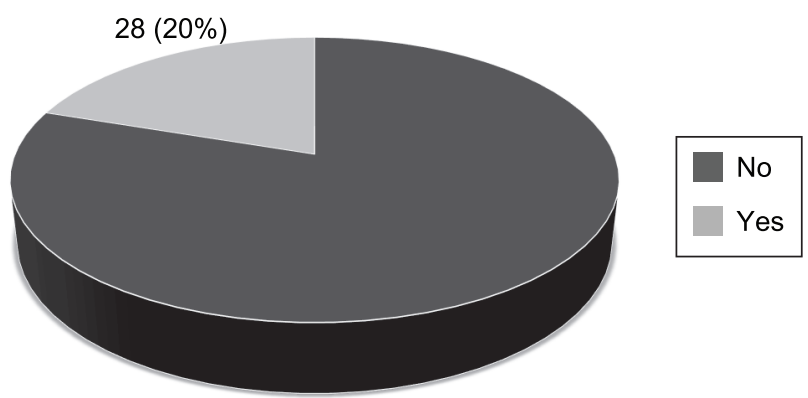

$113(80 \%)$

Fig.-1: Incidence of Pulmonary complication

Table-V

\begin{tabular}{|c|c|c|}
\hline \multicolumn{3}{|c|}{ Pulmonary issues and complications } \\
\hline Variable & Median (IQR) & $\mathrm{n}(\%)$ \\
\hline Fast track extubation & & $75(53.2)$ \\
\hline Duration of MV (hours) & $10.8(4.3-23)$ & \\
\hline Prolonged mechanical ventilation & & $8(5.7)$ \\
\hline Non invasive ventilation & & $8(5.7)$ \\
\hline Re-intubation & & $4(2.8)$ \\
\hline Pneumothorax & & $7(5)$ \\
\hline Pneumothorax requiring ICD & & $5(3.5)$ \\
\hline Pleural effusion & & $12(8.5)$ \\
\hline Pleural effusion requiring ICD & & $9(6.4)$ \\
\hline Subcutaneous emphysema & & $2(1.4)$ \\
\hline
\end{tabular}

Among the study cohort $28(20 \%)$ patients had any form of pulmonary complication [Fig-1]. Table -5 showed detail of pulmonary issues and complications. More than half of the patients, 75(53.2\%) were fast tract extubated. Median duration of mechanical ventilation of the whole study population was 10.8 hours with IQR 4.3 - 23 hours. Eight $(5.7 \%)$ patients required prolonged mechanical ventilation after surgery and another $8(5.7 \%)$ required non invasive ventilation after extubation. Four (2.8\%) patients experienced reintubation. Pneumothorax developed in 7(5\%) patients and among them 5(3.5\%) were severe enough to require intercostal chest tube drainage (ICD). Twelve (8.5\%) patients developed pleural effusion and 3 improved with fluid restriction and diuretic therapy and finally $9(6.4 \%)$ required ICD insertion. Two (1.4\%) patients developed subcutaneous emphysema and improved gradually without any active intervention. 
Table- VI showed patients having pulmonary complications were younger with less body weight, length and BSA in comparison with patients without complications, which is statistically significant ( $\mathrm{p}$ value $<0.05$ ). But there was no statistically significance in sex distribution and pulmonary pressure (PASP) of the patients among the two groups.

Patients having pulmonary complications had higher Aristotle Basic Complexity (ABC) score in comparison to the patient without complication ( $p$ value $<0.01$ ), so is true for RACHS score, higher the RACHS score there was more pulmonary complications ( $p$ value $<0.01$ ). There was no difference in the incidence of pulmonary complication in the type of surgery, either on CPB or off CPB. But among surgery with $\mathrm{CPB}, \mathrm{CPB}$ time and cross clamp time was higher in patients with pulmonary complications ( $p$ value $<0.01$ ). Post operative Inotrope score was not statistically significant in the both groups, but Vasoactive inotrope score, duration of mechanical ventilation, post operative ICU stay and post operative hospital stays were higher in patients with pulmonary complication ( $p$ value $<0.01$ ). [Table-VII]

Table-VI

\begin{tabular}{|c|c|c|c|}
\hline \multicolumn{4}{|c|}{ Relation of Pulmonary complication with demographic characters } \\
\hline & \multicolumn{2}{|c|}{ Pulmonary Complication } & \multirow[t]{2}{*}{$\mathrm{p}$ value ${ }^{\#}$} \\
\hline & Yes & No & \\
\hline Age (months), median (IQR) & $42(20-102)$ & $60(30-156)$ & $<0.05^{*}$ \\
\hline Weight $(\mathrm{kg})($ mean $\pm \mathrm{SD})$ & $14.7 \pm 10.1$ & $22.6 \pm 17.3$ & $<0.01$ \\
\hline Length $(\mathrm{cm})($ mean $\pm \mathrm{SD})$ & $98.7 \pm 29.4$ & $111.7 \pm 32.3$ & $<0.05$ \\
\hline $\mathrm{BSA}($ mean $\pm \mathrm{SD})$ & $0.62 \pm 0.3$ & $0.82 \pm 0.42$ & $<0.01$ \\
\hline \multicolumn{4}{|l|}{ Sex } \\
\hline Male, $\mathrm{n}(\%)$ & $16(11.3)$ & $48(34)$ & $\mathrm{NS}^{\dagger}$ \\
\hline Female, n $(\%)$ & $12(8.5)$ & $65(46.1)$ & \\
\hline $\operatorname{PASP}($ mean $\pm \mathrm{SD})$ & $45.9 \pm 16.7$ & $54.6 \pm 18.1$ & NS \\
\hline
\end{tabular}

\#: Unpaired $t$ test, *: Mann-Whitney $U$ test, $\ddagger$ : Chi-square test, BSA: Body surface area, NS: Not significant

Table-VII

Relation of Pulmonary complication with operative, perfusion and post operative conditions

\begin{tabular}{|c|c|c|c|}
\hline & \multicolumn{2}{|c|}{ Pulmonary Complication } & \multirow[t]{2}{*}{$\mathrm{P}$ value } \\
\hline & Yes $(n=28)$ & No $(n=113)$ & \\
\hline Aristotle score, mean (SD) & $6.7 \pm 2$ & $5 \pm 2$ & $<0.01^{\#}$ \\
\hline \multicolumn{4}{|l|}{ RACSH score $(n=139)^{¥}, n(\%)$} \\
\hline RACHS -1 & $4(6.7)$ & $56(93.3)$ & $<0.01^{\ddagger}$ \\
\hline RACHS -2 & $17(27.9)$ & $44(72.1)$ & \\
\hline RACHS -3 & $6(33.3)$ & $12(66.7)$ & \\
\hline \multicolumn{4}{|l|}{ CPB status, $\mathrm{n}(\%)$} \\
\hline $\mathrm{CPB}$ & $24(17)$ & $93(66)$ & $\mathrm{NS}$ \\
\hline OffCPB & $4(2.8)$ & $20(14.2)$ & \\
\hline CPB time (min) $)^{* *}$, mean $(\mathrm{SD})$ & $119.9 \pm 50.8$ & $85.9 \pm 35.6$ & $<0.01^{\#}$ \\
\hline Cross clamp time (min) $* *$, mean (SD) & $79.1 \pm 33.5$ & $53.8 \pm 27.7$ & $<0.01^{\#}$ \\
\hline Inotrop score, median (IQR) & $4.5(0-5.6)$ & $0(0-5)$ & NS* \\
\hline Vasoactive Inotrope Score, median (IQR) & $8.3(5-21.4)$ & $5(0-5.9)$ & $<0.01 *$ \\
\hline Duration of MV (hours), median (IQR) & $35.3(18.7-132.2)$ & $7.2(3.8-15.4)$ & $<0.01 *$ \\
\hline Post operative ICU stay (days), mean (SD) & $6.9 \pm 5.6$ & $1.9 \pm 1.3$ & $<0.01^{\#}$ \\
\hline Post operative HS (days), mean (SD) & $12.3 \pm 5.9$ & $6.8 \pm 2.7$ & $<0.01^{\#}$ \\
\hline
\end{tabular}

\# Unpaired $t$ test $\quad$ *: Mann-Whitney $U$ test $\quad$ Chi-square test

$¥$ RACHS -4 , there was only 1 patient which was excluded. Another 1 unclassified was also excluded. Finally n=24 in pulmonary complication and $\mathrm{n}=93$ no pulmonary complication.

$* * \mathrm{n}=117$ 


\section{Discussion:}

In this study cohort median age, weight and length of the patients were 60 months, $14.6 \mathrm{~kg}$ and $100 \mathrm{~cm}$ respectively [Table -1$]$. Study from developed country showed a significant percentage for neonates and sucking infants $(<1$ year old) subjected to cardiac surgery ${ }^{5}$. Those facts show that the children in our study were diagnosed and treated late, which is not uncommon in developing countries. Pulmonary complications after surgery for congenital heart disease (CHD) are a recognized entity in literature. Many of the patients have preexisting lung issues related with $\mathrm{CHD}^{6}$. In addition, CHD is often associated with an impaired pulmonary hemodynamic condition that has a great effect on the mechanical properties of the lung ${ }^{7,8}$.

Among the 141 patients of the study population 28 $(20 \%)$ patients had some form of pulmonary complications [Figure - 1] which is within wide range of incidence $(6-76 \%)$ reported in literature ${ }^{3,4,9}$. Most common complication encountered was pleural effusion $(8.5 \%)$ followed by prolonged mechanical ventilation $(5.7 \%)$, requirement of non invasive ventilation (NIV) (5.7\%), pneumothorax (5\%), re-intubation (2.8\%) and subcutaneous emphysema (1.4\%) [Table-V]. There is wide range of incidence of pleural effusion in reported literature. Bocsi et al. showed among 75 children upto 18 years of age undergoing open heart surgery for CHD $29(38.6 \%)$ developed significant pleural effusion ${ }^{10}$. O'Callaghan showed subpleural effusion in $11 \%$ of 83 paediatric patients after cardiac surgery and all of them improved after conservative management and diuretic therapy ${ }^{11}$. Although in our series there was no patient with univentricular repair, Airan et al. showed significant pleural effusion in $27 \%$ of 348 patients with univentricular repair ${ }^{12}$. Children undergoing congenital heart surgery are at risk for prolonged mechanical ventilation ${ }^{13}$ which range from $11-28 \%{ }^{14-16}$. The incidence is little lower in our study (5.7\%) which may be due to less number of neonate and infant in our study.

Non invasive ventilation (NIV) to prevent extubation failure after extubation was required in $5.7 \%$ of patient. The incidence of failed extubation after paediatric cardiac surgery is higher, approaching one-fifth in some groups at high risk compared to the general population treated in the pediatric intensive care unit. Non-invasive ventilation may be used to transition in selected patients from tracheal extubation to ventilation via a natural airway ${ }^{17}$. In a randomized controlled trial Nava et al demonstrated that NIV had a lower rate of re-intubation in comparison to standard medical therapy in patients at risk for post extubation respiratory failure ${ }^{18}$. A Meta analysis of NIV use in selected subgroups of recently extubated patients suggests that the judicious NIV use may reduce ICU and hospital length of stay, pneumonia, re intubation rates and improve hospital survival ${ }^{19}$. Five percent patients in our study developed pneumothorax. Bhat et al. showed $1.8 \%$ patients developing ventilator associated pneumothorax among 540 neonate ${ }^{20}$. In mechanical ventilated patients pneumothorax is not uncommon. Moreover underlying lung diseases and low compliance of lung are associated with ventilatorrelated pneumothorax with pneumothoraces occurring most commonly during the early phase of mechanical ventilation ${ }^{20,21}$.

Patients having pulmonary complications were significantly younger in age and smaller in weight and length ( $p$ value $<0.05$ ) but there was no difference in complications in gender distributions and the finding is similar to Bandla et $\mathrm{al}^{9}$. Younger age is associated with prolonged mechanical ventilation after cardiac surgery in children ${ }^{15}$. Pulmonary complications are also related with complexity of the surgery which has been evident by higher Aristotle scores among the patients with pulmonary complications ( $p$ value $<0.01$ ) as well as higher the RACSH-1 score ( $\mathrm{p}$ value $<0.01$ ). Predictability of post operative mortality and morbidity with higher RACHS- 1 and Aristotle score is shown in different publications ${ }^{22-25}$, although different authors concluded that the Aristotle score is still under development and the reported morbidity scores need to be tested on larger series and in different institutions ${ }^{24,25}$.

There was no difference found in pulmonary complications in relation to whether cardiopulmonary bypass $(\mathrm{CPB})$ required or not, but among the $\mathrm{CPB}$ cases incidence of pulmonary complications are significantly higher ( $\mathrm{P}$ value $<0.01$ ) among longer $\mathrm{CPB}$ time and longer cross clamp time. Lung injury is a recognized complication of $\mathrm{CPB}^{26,27}$. In cardiopulmonary bypass, lung injury follows the propagation of an inflammatory response involving cytokines, complement, neutrophils, monocytes, activated endothelial cells and platelets. Neutrophils sequester in the lung in response to chemotactic agents and release injurious free radicals and 
specific enzymes resulting in widespread pulmonary injury $^{28}$. CPB and aortic clamping led to significant decreases in functional residual capacity (FRC), which later improve slightly but remain significantly lower than the baseline value ${ }^{29}$. However Stayer et al. did not find any effect of duration of $\mathrm{CPB}$ on respiratory mechanics, but longer aortic cross-clamp time was associated with decreased respiratory compliance ${ }^{7}$. In our series, inotrope scores are similar in the both groups and vasoactive inotrope scores (VIS) are higher ( $p$ value $<0.01$ ) among patients with pulmonary complications. Vasoactive-inotropic score is an independent predictor of clinical outcome in infants after cardiac surgery and high vasoactive-inotropic score was found associated with prolonged intensive care stay and duration of mechanical ventilation. On the other hand role of the inotrope score is yet to be established as a predictor of outcome ${ }^{30}$.

Post operative pulmonary complication is one of the most important post operative morbidity which significantly affects outcomes. In our study, patients who suffered any form of pulmonary complications had longer duration of mechanical ventilation $(p<0.01)$, longer post operative ICU stay $(\mathrm{p}<0.01)$ and longer post operative hospital stay $(\mathrm{p}<0.01)$. Studies also showed that pulmonary complications are a frequent cause for delayed recovery following cardiac surgery and including prolonged duration of mechanical ventilation specially in young children and prolonged ICU stay ${ }^{9,31}$.

\section{Conclusion:}

Pulmonary complications are common after surgery for CHD. In young children undergoing surgical repair is clearly associated with pulmonary involvement. Complex surgeries, longer CPB \& cross clamp time and higher vasoactive inotrope score are also associated with increased incidence of pulmonary complications which significantly affect outcomes including prolonged duration of mechanical ventilation, prolonged post operative ICU stay and post operative hospital stay.

\section{Limitations:}

This is an initial report from departmental congenital heart surgery database over very short period of time from a single institute. Longer duration of study with larger population from multiple centers is required for stronger evidences.

\section{Acknowledgement:}

Department of Community medicine, Epidemiology and Research; National Heart Foundation Hospital and Research Institute for assistance during data analysis process.

\section{References:}

1. Radhakrishnan S, Shrivastava S. Non surgical treatment in congenital heart disease. Indian J Pediatr 1998;65: 195-210

2. Antonio FC. Surgery for congenital heart disease. Current Opinion in Cardiology 2000;15:238-43

3. Borges DL, Sousa LRT, Silva RT, Gomes HCR, Ferreira FMM, Lima WL, et al. Pulmonary complications in pediatric cardiac surgery at a university hospital. Rev Bras Cir Cardiovasc 2010; 25(2): 234-237

4. Cruz BDD, De Leon NA, Policarpio T, Reyes AM, De Leon AR, Requiron D, et al. A proposed pediatric risk stratification method (PediaRism) for post operative pulmonary complication for cardiothoracic surgery. Phil Heart Center J 2012;16:35-46

5. Boethig D, Jenkins KJ, Hecker H, Thies WR, Breymann T. The RACHS-1 risk categories reflect mortality and length of hospital stay in a large German pediatric cardiac surgery population. Eur J Cardiothorac Surg. 2004;26(1):12-7.

6. J I Hoffman, A M Rudolph, M A Heymann. Pulmonary vascular disease with congenital heart lesions: pathologic features and causes. Circulation 1981; 64: 873-877

7. Stayer SA, Diaz LK, East DL, Gouvion JN, Vencill TL, McKenzie ED, et al. Changes in respiratory mechanics among infants undergoing heart surgery. Anesth Analg. 2004;98:49-55

8. Habre W, Schutz N, Pellegrini M, Beghetti M, Sly PD, Hantos Z, et al. Preoperative pulmonary hemodynamics determines changes in airway and tissue mechanics following surgical repair of congenital heart diseases. Pediatr Pulmonol. 2004;38:470-6.

9. Bandla HP, Hopkins RL, Beckerman RC, Gozal D. Pulmonary risk factors compromising postoperative recovery after surgical repair for congenital heart disease. Chest. 1999 Sep;116:740-7.

10. Bocsi J, Hambsch J, Osmancik P, Schneider P, Valet G, Tárnok A. Preoperative prediction of pediatric patients with effusions and edema following cardiopulmonary bypass surgery by serological and routine laboratory data. Crit Care. 2002;6:226-33

11. O'Callaghan C, Cooke J, Kerr IH, Shinebourne EA. Subpulmonary pleural effusions in children after cardiac surgery. Br Heart J. 1985;54:593-5 
12. Airan B, Sharma R, Choudhary SK, Mohanty SR, Bhan A, Chowdhari UK, et al. Univentricular repair: Is routine fenestration justified? Ann Thorac Surg. 2000;69:1900-6

13. Ong T, Stuart-Killion RB, Daniel BM, Presnell LB, Zhuo H, Matthay MA, et al. Higher pulmonary dead space may predict prolonged mechanical ventilation after cardiac surgery. Pediatr Pulmonol. 2009;44:457-63.

14. García-Montes JA, Calderón-Colmenero J, Casanova M, Zarco E, de la Reguera GF, Alfonso Buendía A. Risk factors for prolonged mechanical ventilation after surgical repair of congenital heart disease. Arch Cardiol Mex 2005; 75: 402-407

15. Polito A, Patorno E, Costello JM, Salvin JW, Emani SM, Rajagopal S, et al. Perioperative factors associated with prolonged mechanical ventilation after complex congenital heart surgery. Pediatr Crit Care Med 2011;12:e122-6.

16. Davis S, Cox AC, MD, Piedmonte M, Drummond-Webb JJ, Mee RBB, A. Marc Harrison AM. Prolonged Mechanical Ventilation after Cardiac Surgery in Young Children: Incidence, Etiology, and Risk Factors. J Intensive Care Med 2002;17:302-7

17. Cooper DS, Costello JM, Bronicki RA, Stock AC, Jacobs JP, Ravishankar C, et al. Current challenges in cardiac intensive care: optimal strategies for mechanical ventilation and timing of extubation. Cardiol Young 2008; 18(Suppl. 3): 72-83

18. Nava S, Gregoretti C, Fanfulla F, Squadrone E, Grassi M, Carlucci A, et al. Noninvasive ventilation to prevent respiratory failure after extubation in high-risk patients. Crit Care Med 2005; 33:2465-2470

19. Glossop AJ, Shepherd N, Bryden DC, Mills GH. Noninvasive ventilation for weaning, avoiding reintubation after extubation and in the postoperative period: a metaanalysis. Br. J. Anaesth. 2012; 109 : 305-314.

20. Bhat Yellanthoor R, Ramdas V. Frequency and intensive care related risk factors of pneumothorax in ventilated neonates. Pulm Med. 2014;2014:727323. doi: 10.1155/ 2014/727323. Epub 2014 Apr 28.

21. Hsu CW, Sun SF. Iatrogenic pneumothorax related to mechanical ventilation. World J Crit Care Med. 2014 Feb $4 ; 3(1): 8-14$
22. Kanga N, Coleb T, Tsanga V, Elliotta M, de Levala M. Risk stratification in paediatric open-heart surgery. Eur $\mathrm{J}$ Cardiothoracic Surg 2004;26:3-11

23. Jenkins KJ, Gauvreau K, Newburger JW, Spray TL, Moller JH, Iezzoni LI. Consensus-based method for risk adjustment for surgery for congenital heart disease. J Thorac Cardiovasc Surg 2002;123:110-8

24. Sataa S, Haunb C, Weberc T, Arenza C, Photiadisa J, Hraskaa V. A morbidity score for congenital heart surgery based on observed complications. Eur J Cardiothorac Surg 2012; 41: $898-904$

25. Heinrichsa J, Sinzobahamvyaa N, Arenza C, Kallikourdisa A, Photiadisa J, Schindlerb E. Surgical management of congenital heart disease: evaluation according to the Aristotle score. Eur J Cardiothorac Surg 2010; 37: 210-7.

26. Leukocyte depletion ameliorates free radical-mediated lung injury after cardiopulmonary bypass. Bando K, Pillai R, Cameron DE, Brawn JD, Winkelstein JA, Hutchins GM, et al. J Thorac Cardiovasc Surg 1990, 99:873-7

27. Asimakopoulosa G, Smitha PLC, Ratnatungaa CP, Taylor KM. Lung injury and acute respiratory distress syndrome after cardiopulmonary bypass. Ann Thorac Surg 1999;68: 1107-1115

28. Clark SC. Lung Injury after Cardiopulmonary Bypass. Perfusion 2006;4:225-228

29. von Ungern-Sternberg BS, Petak F, Saudan S, Pellegrini M, Erb TO, Habre W. Effect of cardiopulmonary bypass and aortic clamping on functional residual capacity and ventilation distribution in children. J Thorac Cardiovasc Surg 2007;134:1193-8

30. Gaies MG, Gurney JG, Yen AH; Napoli ML, Gajarski RJ, Ohye RG, et al. Vasoactive-inotropic score as a predictor of morbidity and mortality in infants after cardiopulmonary bypass. Pediatr Crit Care Med 2010; $11: 234-238$

31. Pagowska-Klimek I, Pychynska-Pokorska M, Krajewski W, Moll JJ. Predictors of long intensive care unit stay following cardiac surgery in children. Eur J Cardiothorac Surg. 2011 Jul;40(1):179-84. 